\title{
Infrared spectra of $\mathrm{Si}-\mathrm{O}$ overtones, hydrous species, and $U$ ions in metamict zircon: radiation damage and recrystallization
}

\author{
Ming Zhang ${ }^{1,3}$, Ekhard K H Salje ${ }^{1}$ and Rodney C Ewing ${ }^{2}$ \\ ${ }^{1}$ Department of Earth Sciences, University of Cambridge, Downing Street, \\ Cambridge CB2 3EQ, UK \\ 2 Department of Nuclear Engineering and Radiological Sciences, Department of Geological \\ Sciences, University of Michigan, Ann Arbor, MI 48109-2104, USA \\ E-mail: mz10001@esc.cam.ac.uk
}

Received 21 November 2001

Published 15 March 2002

Online at stacks.iop.org/JPhysCM/14/3333

\begin{abstract}
Radiation damage and recrystallization in natural zircons have been studied by analysing $\mathrm{Si}-\mathrm{O}$ stretching overtones/combinations, hydrous species, and U-ion spectra in the frequency region between 1200 and $11000 \mathrm{~cm}^{-1}$. The effects of radiation are characterized by a dramatic variation of intensity, a decrease in frequencies of multi-phonon bands (e.g., Si-O stretching overtones), a change of spectral profile of $\mathrm{OH}$ species, a formation of new $\mathrm{OH}$ species, and new signals related to $\mathrm{U}$ ions. The formation of new anisotropic $\mathrm{OH}$ species in the crystalline regions of metamict zircon is observed and this could account for the different thermal behaviour of $\mathrm{OH}$ species between metamict zircon and titanite during high-temperature annealing. The results imply systematic modifications of the local environments of the $\mathrm{OH}$ and $\mathrm{U}$ ions in the damage process. Both $\mathrm{U}^{4+}$ and $\mathrm{U}^{5+}$ spectra show dramatic variations during metamictization. We observe, for the first time, that as a result of radiation damage, the $\mathrm{U}^{5+}$ signals near 6668 and $9030 \mathrm{~cm}^{-1}$ become undetectable at a dose of around $1.5 \times 10^{18} \alpha$ events $\mathrm{g}^{-1}$ while extra lines near 6650 and $8969 \mathrm{~cm}^{-1}$ appear. These variations are interpreted as radiation-induced local modifications in crystalline regions. The general shape of the $\mathrm{U}$-ion spectrum of the crystalline zircon is somehow still preserved in highly damaged zircon. A decomposed zircon, consisting of $\mathrm{ZrO}_{2}, \mathrm{SiO}_{2}$, and $\mathrm{ZrSiO}_{4}$, shows spectral features different from those of metamict zircon samples. Thermal annealing of a highly damaged zircon leads to recovery of the structure of zircon, indicated by spectral changes of multiphonon bands and $\mathrm{U}$ ions, accompanied with the appearance of new $\mathrm{OH}$ species. The results confirm that the recrystallization process in heavily damaged zircon involves the decomposition of metamict $\mathrm{ZrSiO}_{4}$ into $\mathrm{SiO}_{2}$ and $\mathrm{ZrO}_{2}$ near $1100 \mathrm{~K}$ and the significant crystal growth of $\mathrm{ZrSiO}_{4}$ near $1400 \mathrm{~K}$ as indicated by the recovery of $\mathrm{Si}-\mathrm{O}$ stretching overtones and $\mathrm{U}^{4+}$ and $\mathrm{U}^{5+}$ bands.
\end{abstract}

3 Author to whom any correspondence should be addressed. 


\section{Introduction}

Zircon $\left(\mathrm{ZrSiO}_{4}\right)$ is tetragonal with space group $\mathrm{D}_{4 \mathrm{~h}}^{19}$ or $I 4_{1} /$ amd and $Z=4$ (Hazen and Finger 1979). It has been proposed as a candidate for use in the immobilization and disposal of high-actinide nuclear wastes and weapons-grade $\mathrm{Pu}$. Natural zircon $\left(\mathrm{ZrSiO}_{4}\right)$ commonly contains U, Th, and other rare-earth elements. Due to radioactive decay of naturally occurring radionuclides and their daughter products in the ${ }^{238} \mathrm{U},{ }^{235} \mathrm{U}$, and ${ }^{232} \mathrm{Th}$ decay series, natural minerals can be heavily damaged over geological times, resulting in an aperiodic or amorphous state - the metamict state (Ewing 1994, Salje et al 1999). Extensive investigations were carried out in order to gain a better understanding of the damage mechanism of zircon (Holland and Gottfried 1955, Murakami et al 1991, Woodhead et al 1991a, Farges 1994, Weber et al 1994, Meldrum et al 1998, Salje et al 1999, Ríos et al 2000, Zhang et al 2000c, Zhang and Salje 2001), the structural state of the amorphized phase (Farnan and Salje 2001, Trachenko et al 2001, Zhang and Salje 2001), and the recrystallization path (Weber 1991, Ellsworth et al 1994, Colombo et al 1999, Zhang et al 2000a, 2000b, Geisler et al 2001).

As a part of our recent systematic study of metamictization and recrystallization of zircon using Raman and infrared (IR) spectroscopy (e.g., Raman studies by Zhang et al (2000a, 2000c); and mid-infrared (MIR) and far-infrared (FIR) studies by Zhang et al (2000b) and Zhang and Salje (2001)), we undertook this near-infrared (NIR) study to gain further understanding of the damage and recrystallization processes in metamict zircon. Our principal objectives were as follows.

(1) It was reported that in the $\mathrm{Si}-\mathrm{O}$ overtone region, spectral features of metamict zircon appeared similar to those of $\mathrm{SiO}_{2}$ glass, although neither $\mathrm{SiO}_{2}$ nor $\mathrm{ZrO}_{2}$ were detected in metamict zircons (Vance 1975). Furthermore, IR data from the fundamental Si-O stretching bands between 800 and $1200 \mathrm{~cm}^{-1}$ showed spectral features very different from those of $\mathrm{SiO}_{2}$ glass (Zhang et al 2000b, Zhang and Salje 2001). We wish to gain structural information through characteristic spectral changes related to multi-phonon processes, and to investigate the spectral similarities or differences among metamict zircon, decomposed zircon, and $\mathrm{SiO}_{2}$ glass.

(2) In natural zircon, hydrogen has been found incorporated into the crystal structure, and U atoms can replace $\mathrm{Zr}$ atoms and still hold the $\mathrm{D}_{2 \mathrm{~d}}$ site symmetry. Thus both $\mathrm{OH}$ and $\mathrm{U}$ ions exist as defects in natural zircon, and their characteristic spectral features are sensitive to the alternations of the crystal structure of zircon. We wish to understand the impact of radiation damage on crystal defects in zircon through analysing $\mathrm{OH}$ species and $\mathrm{U}$ ions, and to gain information on the structural change in metamictization from the variations of the defect spectra.

(3) IR spectroscopic studies have shown differences in thermal behaviour of the $\mathrm{OH}$ species between metamict zircon and metamict titanite $\left(\mathrm{CaTiSiO}_{5}\right)$. New $\mathrm{OH}$ species tend to form in metamict zircon during recrystallization at high temperatures (Woodhead et al 1991b), whereas annealing of metamict titanite leads to an increase in intensity from the original $\mathrm{OH}$ species existing in crystalline titanite (Salje et al 2000, Zhang et al 2001). We aim to gain a further understanding of the effects of radiation damage on $\mathrm{OH}$ species, and to explore what the possible structural changes causing these effects are.

\section{Experimental details}

The samples used in this study were analysed by electron microprobe, $\mathrm{x}$-ray, and IR spectroscopy. They have been previously characterized (Murakami et al 1991, Ellsworth 
et al 1994, Ríos and Salje 1999, Salje et al 1999, Ríos et al 2000, Zhang et al 2000a, 2000b, 2000c, Zhang and Salje 2001). The lattice parameters of some samples were determined by $\mathrm{X}$-ray Guinier powder diffraction with $\mathrm{Si}$ as an internal standard. Electron microprobe analysis was performed on polished thin sections of zircon samples using a Cameca SX5D electron microprobe with a Link AN10000 energy-dispersive spectrometer. A beam size of $5 \mathrm{~mm}$ was used with a beam current of $100 \mathrm{nA}$. The samples used are mainly crystals from Sri Lanka because they were of gem quality and contained low chemical impurity levels.

Zircon crystals with gem quality or close to gem quality and with no cracks were selected. The crystallographic orientations of the crystals were determined from the external morphology or using x-ray precession techniques and an optical polarizing microscope. It was impossible to orient samples with doses higher than $10 \times 10^{18} \alpha$-events $\mathrm{g}^{-1}$ as there were no Bragg reflections and these high-dose samples all had irregular external shapes. Crystal zircon plates were cut parallel to the $c$-axis and were then polished.

High-temperature annealing experiments were carried out in $\mathrm{N}_{2}$ atmosphere in a vertical furnace. The annealing temperature was measured with a Pt-PtRh thermocouple that was placed just above the samples. The sample was annealed at a high temperature for $1 \mathrm{~h}$ and then quenched in air. After experiments at room temperature, the samples were annealed at a higher temperature. A Leybold two-stage closed-cycle helium cryostat with a working temperature range of 13-310 K was used for in situ low-temperature measurements (Zhang et al 1996). The cryostat was coupled with a Leybold TLC60 temperature controller and a Leybold cryo-compress. A sample holder was made from high-thermal-conductivity oxygenfree copper. A gold-coated lattice made from oxygen-free copper was installed at the sample position to improve the thermal contact between the sample and the sample holder. One temperature sensor, positioned near the heating unit, was used to control the temperature of the cryostat while another Si-diode temperature sensor (LakeShore, DT-470-DI-13, calibrated by the manufacturer) was glued on the centre of the sample holder for measuring the sample temperature. The temperature stability is better than $0.2 \mathrm{~K}$. The sample was placed in a vacuum chamber equipped with KRS5 windows.

Two IR spectrometers were used. A Bruker FT-IR 66v spectrometer was used to record the IR spectra between 500 and $11000 \mathrm{~cm}^{-1}$ at room temperature. A liquid-nitrogen-cooled MCT detector, coupled with a $\mathrm{KBr}$ beam splitter and a Globar source, was used to record the spectra between 500 and $5000 \mathrm{~cm}^{-1}$. For the frequency region of 3000-11000 cm $\mathrm{cm}^{-1}$, a tungsten source, an MCT detector, and $\mathrm{CaF}_{2}$ beam splitter were used with a spectral resolution of $4 \mathrm{~cm}^{-1}$. A KRS5 wire-grid polarizer was employed. All the spectra were averaged over 512 scans. A Bruker 113v IFS FT-IR spectrometer was used to record polarized and unpolarized IR spectra between 1300 and $4500 \mathrm{~cm}^{-1}$ at low temperatures. An instrumental resolution of $2 \mathrm{~cm}^{-1}$ and 350 scans were adopted. Sample and reference single-beam spectra measured at the same temperatures were used for calculating the absorption spectra. All absorption spectra were recorded as absorbance $\alpha$, with $\alpha=-\log _{10}\left(I_{\text {sample }} / I_{\text {reference }}\right)$, where $I$ is the single-beam transmission intensity. The software OPUS-IR was used for data analysis.

\section{Analysis and results}

\subsection{Effect of radiation damage on multi-phonons}

Polarized IR data between 1500 and $4000 \mathrm{~cm}^{-1}$ are plotted in figure 1. The IR spectra show two groups of separated spectral features, and they are located between 1500 and $2700 \mathrm{~cm}^{-1}$ and 3000 and $3600 \mathrm{~cm}^{-1}$, respectively. The former is mainly due to multi-phonon interactions from the framework of zircon, whereas the latter can be mainly assigned as $\mathrm{OH}$ species (Dawson 
Table 1. Multi-phonon bands of crystalline and weakly damaged zircon between 1350 and $2100 \mathrm{~cm}^{-1}$. Sample dosages are in units of $10^{18} \alpha$-events $\mathrm{g}^{-1}$. Some weak bands are undetectable in the sample with the dose of $1.8 \times 10^{18} \alpha$-events $\mathrm{g}^{-1}$. UD $=$ undetectable.

\begin{tabular}{clllll}
\hline & \multicolumn{2}{c}{$\boldsymbol{E} \perp \boldsymbol{c}$} & & \multicolumn{2}{c}{$\boldsymbol{E} \| \boldsymbol{c}$} \\
\cline { 2 - 3 } \cline { 5 - 6 } Sample dose & 0.06 & 1.8 & & 0.06 & 1.8 \\
\hline & 1374 & UD & & 1395 & UD \\
& 1388 & UD & & 1445 & UD \\
1442 & 1440 & & 1546 & 1533 \\
1516 & 1503 & & 1594 & 1584 \\
1596 & 1588 & & 1624 & 1613 \\
1624 & 1616 & & 1661 & 1651 \\
1681 & UD & & 1782 & 1760 \\
1720 & UD & & 1838 & 1815 \\
1838 & 1815 & & 1878 & 1878 \\
1873 & 1856 & & 1909 & UD \\
1900 & 1893 & & 1946 & 1934 \\
1953 & 1939 & & 1991 & UD \\
1994 & 1986 & 2019 & 2001 \\
1986 & UD & 2046 & 2032 \\
2067 & 2052 & & \\
\hline
\end{tabular}

et al 1971, Woodhead et al 1991a, 1991b). The signals between 1350 and $2100 \mathrm{~cm}^{-1}$ (their peak positions are listed in table 1) are mainly related to two-phonon processes (first overtones and combinations) (Dawson et al 1971), and the absorption near $2700 \mathrm{~cm}^{-1}$ was assigned to the three-phonon process that was used to determine the degree of radiation damage in natural zircon by Woodhead et al (1991a).

The effects of radiation damage on the crystal structure of zircon are characterized by a dramatic decrease in intensity, and significant line broadening of the two-phonon-interaction bands of Si-O stretching between 1500 and $2100 \mathrm{~cm}^{-1}$ (figures 1, 2(a) and $(b)$ ). In particular, the frequencies related to the two-phonon interactions decrease systematically with increasing radiation dose. This observation is consistent with the observations from Raman bands of zircon (Zhang et al 2000c), which show a significant decrease of Si-O stretching vibrations in damaged zircon. Radiation damage of zircon is also characterized by systematic changes of the absorption coefficient of the minimum near $1670 \mathrm{~cm}^{-1}$ and the local maximum near $1873 \mathrm{~cm}^{-1}$ (the maximum, in fact, shifts to $1813 \mathrm{~cm}^{-1}$ for heavily damaged zircon) for $\boldsymbol{E} \perp \boldsymbol{c}$. The absorption coefficients of the signals are plotted as a function of radiation dose (figures 3(a), $(b)$ ). The data shown in figure 3(a) can be used to estimate the degree of damage. We were surprised to note that the dose dependence of the absorption coefficient at $1666 \mathrm{~cm}^{-1}$ (i.e., $\sim 6 \mu \mathrm{m}$ ) reported by Wasilewski et al (1973) gave much higher values of the coefficient than ours for damaged samples, especially at high doses. For example, a value of $62.9 \mathrm{~cm}^{-1}$ for the coefficient was reported for a sample with a radiation dose of $8.3 \times 10^{18}$ $\alpha$-events $\mathrm{g}^{-1}$, and an error of $10 \%$ was estimated (Wasilewski et al 1973). Their absorption coefficient is almost double the value we obtained for a sample with a similar value of radiation dose. In order to check the accuracy of our measurements, the measured absorption coefficient of a sample with a dose value of $11.7 \times 10^{18} \alpha$-events $\mathrm{g}^{-1}$, which was previously measured by Aines and Rossman (1986) and Woodhead et al (1991a), was compared with the results of these two previous investigations. The coefficient from our measurement is consistent with those of Aines and Rossman (1986) and Woodhead et al (1991a). The difference between our measurement and those of Aines and Rossman (1986) and Woodhead et al (1991a) is less than 


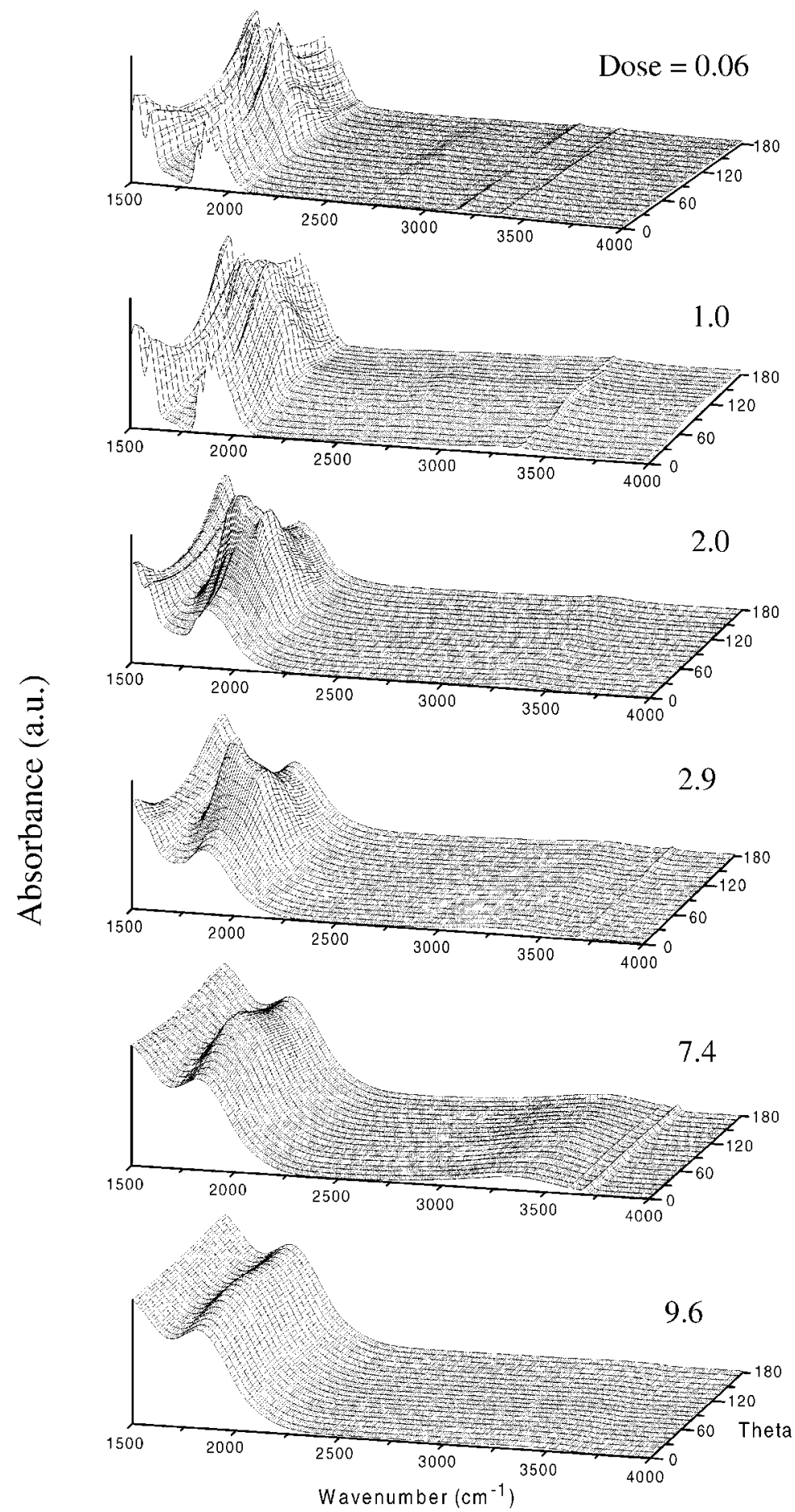

Figure 1. Polarized IR spectra between 1500 and $4000 \mathrm{~cm}^{-1}$ for zircon samples with different degrees of radiation damage. $\theta$ is the angle between the electric field, $\boldsymbol{E}$, and the $\boldsymbol{c}$-axis. It varies from 0 to $180^{\circ}$. The dose values (in units of $10^{18} \alpha$-events $\mathrm{g}^{-1}$ ) are given in the plot. The sample with a dose value of $9.6 \times 10^{18} \alpha$-events $\mathrm{g}^{-1}$ still shows a weak orientational dependence. 


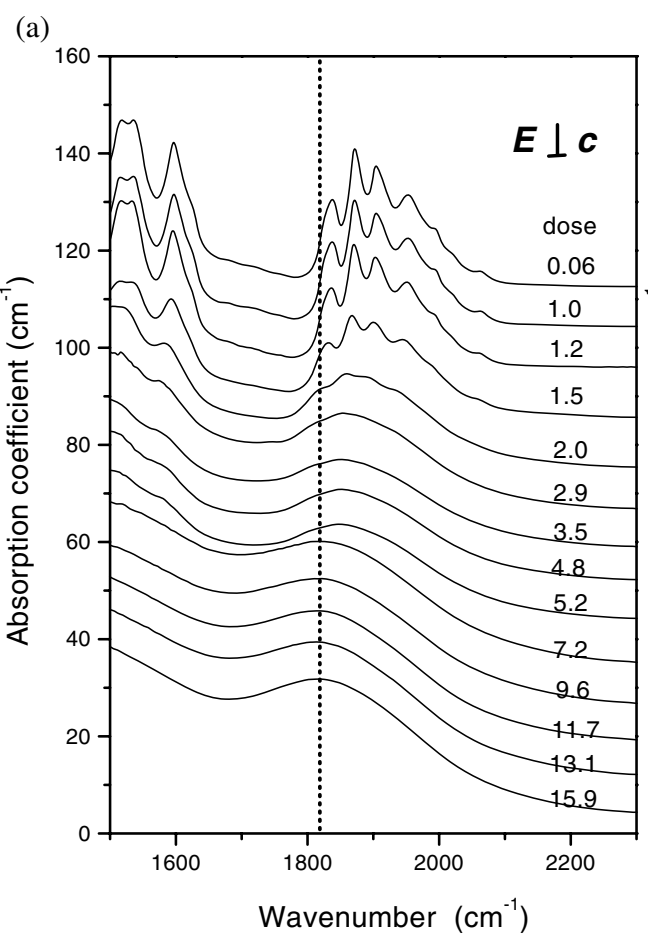

(b)

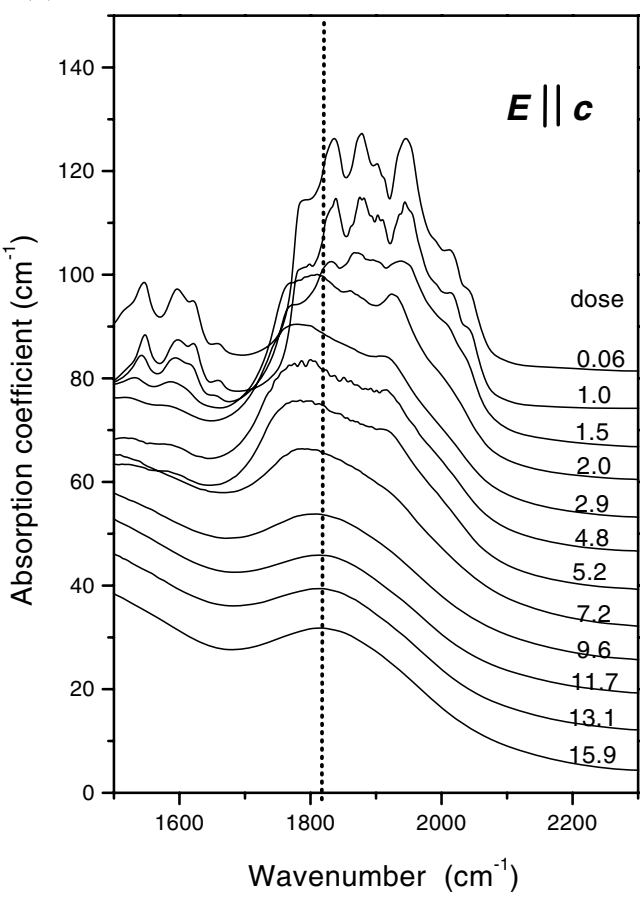

Figure 2. Effects of radiation damage on the IR bands due two-phonon interactions of Si-O stretching. The polarized spectra of samples with doses higher than $10 \times 10^{18} \alpha$-events $\mathrm{g}^{-1}$ were obtained from sample plates with unknown crystallographic orientations, as they are isotropic. (a) $\boldsymbol{E} \perp c ;$; b) $\boldsymbol{E} \| \boldsymbol{c}$.

4\%. We consider that the systematic difference between the data of Wasilewski et al (1973) and the three later measurements could be due to possible experimental errors. The values from Aines and Rossman (1986), Woodhead et al (1991a), and ours are more reliable and are fully reproducible.

The radiation-induced loss of anisotropy is shown in figure 1. The spectral features of the two-phonon bands between 1500 and $2100 \mathrm{~cm}^{-1}$ become more and more isotropic. However, a sample with a dose of $9.6 \times 10^{18} \alpha$-events $\mathrm{g}^{-1}$ still shows a weak orientational dependence (figure 1). It is impossible to align crystallographically crystals with doses higher than $10 \times 10^{18} \alpha$-events $\mathrm{g}^{-1}$ for the reasons described in the previous section. Polarized spectra measured at different polarization directions appear to show similar spectral features. This is consistent with results from polarized reflectance spectra between 650 and $1500 \mathrm{~cm}^{-1}$ (Zhang et al 2000b).

\subsection{OH species}

Crystalline zircon from Sri Lanka shows OH bands near 3176, 3417, and $3510 \mathrm{~cm}^{-1}$ for $\boldsymbol{E} \| \boldsymbol{c}$, 3179,3386 , and $3504 \mathrm{~cm}^{-1}$ for $\boldsymbol{E} \perp \boldsymbol{c}$ (figures $4(a)$ and $(b)$ ). The 3417 and $3386 \mathrm{~cm}^{-1}$ bands are associated with Si-occupied tetrahedra (Woodhead et al 1991b). The $3417 \mathrm{~cm}^{-1}$ band $(\boldsymbol{E} \| \boldsymbol{c})$ and the $3504 \mathrm{~cm}^{-1}$ band $(\boldsymbol{E} \perp \boldsymbol{c})$ have frequencies similar to those of the $\mathrm{OH}$ stretching band in synthetic hydroxylated zircon reported by Caruba et al (1985). This observation could imply the possible occurrence of the hydrogrossular substitution. As the bands are weak, 


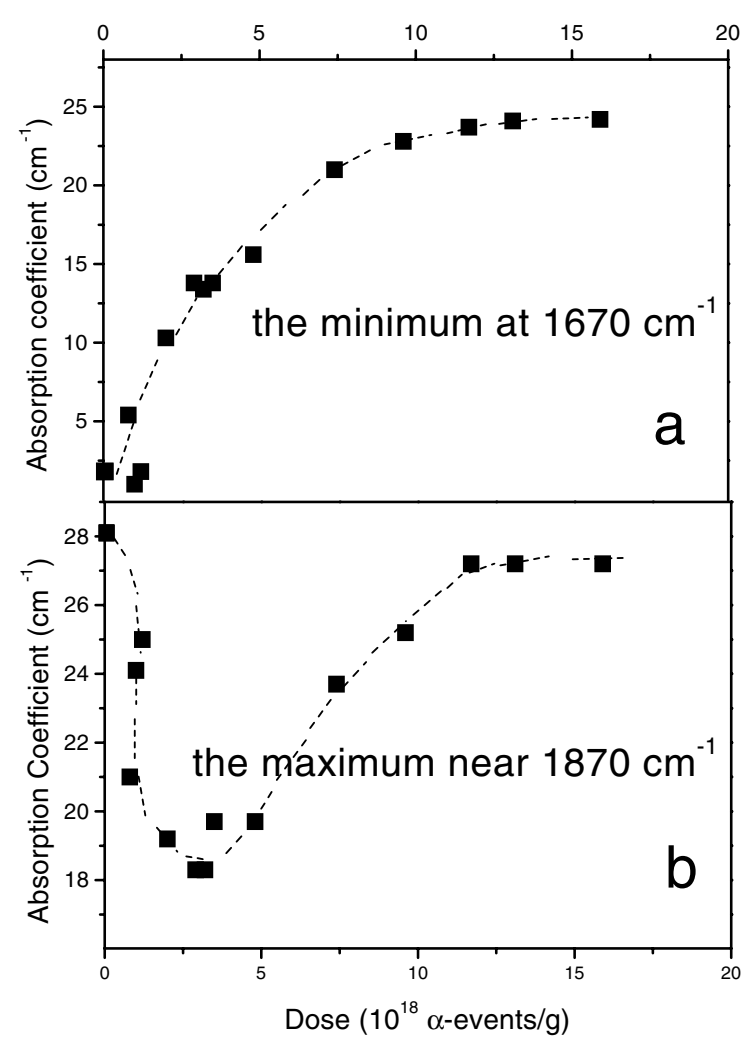

Figure 3. Dose dependences of the spectral profile with $\boldsymbol{E} \perp \boldsymbol{c}$. (a) The absorption coefficient of the minimum near $1670 \mathrm{~cm}^{-1} ;(b)$ the absorption coefficient of the peak maximum near $1870 \mathrm{~cm}^{-1}$. Dosage is in the units of $10^{18} \alpha$-events $\mathrm{g}^{-1}$.

they are unlikely to play important roles in the assessment of $\mathrm{OH}$ contents in these samples. The effects of radiation damage on zircon are also characterized by spectral variations in $\mathrm{OH}$ bands (figure 1). Our results reveal that with increasing degree of damage, $\mathrm{OH}$ spectra exhibit the following two types of significant change. (1) The disappearance or line broadening of the sharp signals near 3179 and $3386 \mathrm{~cm}^{-1}$ with $\boldsymbol{E} \perp \boldsymbol{c}$ and $3417 \mathrm{~cm}^{-1}$ with $\boldsymbol{E} \| \boldsymbol{c}$, accompanied with the occurrence a broad feature in the region of 3000 and $3600 \mathrm{~cm}^{-1}$ at doses between 1.0 and $1.5 \times 10^{18} \alpha$-events $\mathrm{g}^{-1}$. (2) A systematic development of absorption signals near $3560 \mathrm{~cm}^{-1}$ between 4.5 and $10 \times 10^{18} \alpha$-events $\mathrm{g}^{-1}$ as indicated by arrows (figures $4(a)$ and $(b)$ ). Samples with doses higher than $10 \times 10^{18} \alpha$-events $\mathrm{g}^{-1}$ appear to show basically identical $\mathrm{OH}$ features. Similar spectral features were reported for highly damaged zircon by Aines and Rossman (1986) and Woodhead et al (1991b). We note that the effect of radiation damage on the $\mathrm{OH}$ species in zircon appears more complex and different from those in titanite. In titanite, the $\mathrm{OH}$ species eventually show a superposition of signals from crystalline and amorphous regions (Zhang et al 2001), but this behaviour is not observed in zircon.

Three samples (with doses of $1.5,4.8$, and $15.9 \times 10^{18} \alpha$-events $\mathrm{g}^{-1}$, respectively) were measured at low temperatures between 20 and $300 \mathrm{~K}$ in order to resolve the $\mathrm{OH}$ species and to identify the possible peak positions for their broad $\mathrm{OH}$ features (figures $5(a)-(c)$ ). The slightly damaged sample (with a dose of $1.5 \times 10^{18} \alpha$-events $\mathrm{g}^{-1}$ ) exhibits the strongest response to 


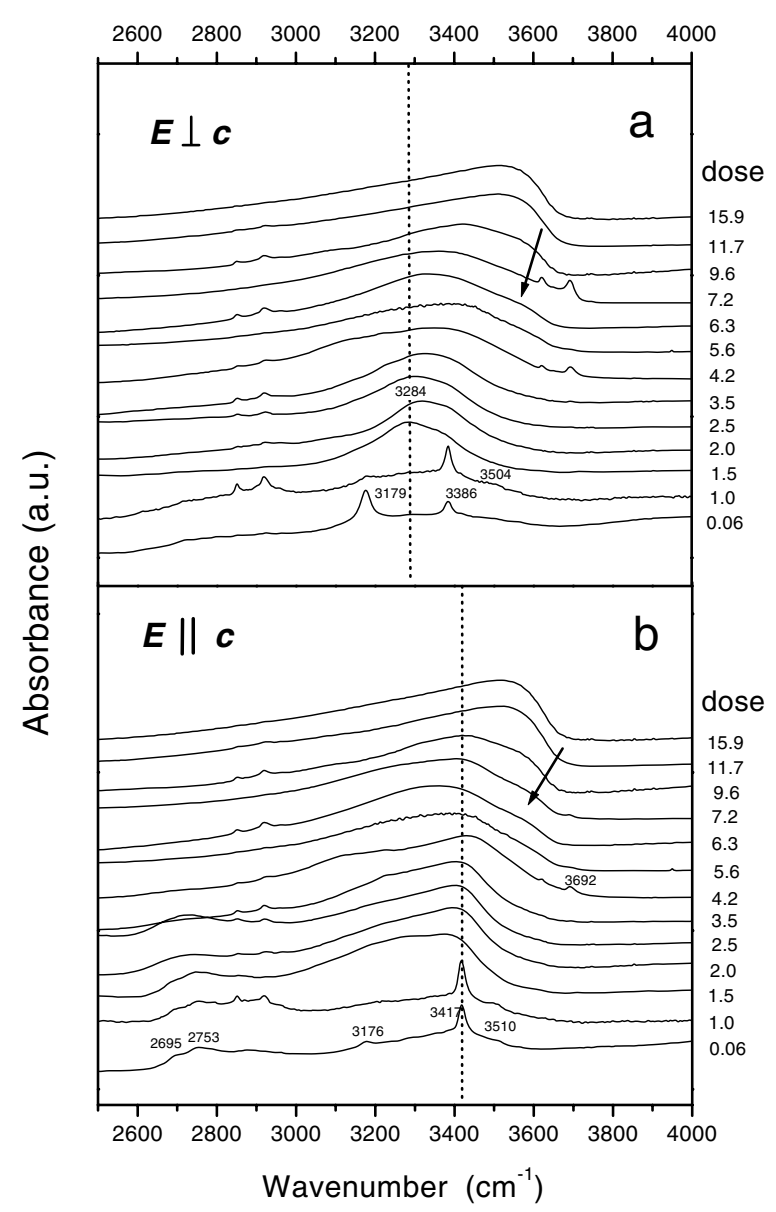

Figure 4. Infrared spectra of hydrous species for Sri Lanka zircons with different degrees of radiation damage in the region of 2500 and $4000 \mathrm{~cm}^{-1}$. The spectra are normalized by height to show detailed changes. OH species show a dramatic change of the spectral patterns near $1.5 \times 10^{18}$ $\alpha$-event $\mathrm{g}^{-1}$. Additional absorption near $3560 \mathrm{~cm}^{-1}$ as indicated by the arrows gradually develops between 4.5 and $10 \times 10^{18} \alpha$-events $\mathrm{g}^{-1}$ and it shows a systematic increase of absorbance with increasing dose. The features near 2847 and $2817 \mathrm{~cm}^{-1}$ are artifacts caused by the beam splitter. (a) $\boldsymbol{E} \perp \boldsymbol{c} ;(b) \boldsymbol{E} \| \boldsymbol{c}$

decreasing temperature: the broad $\mathrm{OH}$ features between 3000 and $3600 \mathrm{~cm}^{-1}$ become sharp, showing individual peaks centred at 3298, 3336, and $3406 \mathrm{~cm}^{-1}$ for $\boldsymbol{E} \perp \boldsymbol{c}$, and 3183, 3280, and $3406 \mathrm{~cm}^{-1}$ for $\boldsymbol{E} \| \boldsymbol{c}$. These new $\mathrm{OH}$ species were not observed in samples with lower dose values, and they could result from local structural modifications in this sample. For the two more damaged samples, cooling to $20 \mathrm{~K}$ did not cause significant changes in peak profiles although the spectra of the samples recorded at $20 \mathrm{~K}$ show slightly higher integrated absorbance (2-4\%) between 2500 and $3800 \mathrm{~cm}^{-1}$ than those measured at $300 \mathrm{~K}$. This suggests that $\mathrm{OH}$ species of damaged samples are weakly temperature dependent. Similar observations have been made during an in situ IR study of metamict titanite at low temperatures (Zhang et al 2000d).

Due to lack of calibration between IR absorption and $\mathrm{OH}$ contents for zircon, we used the calibrations of Paterson (1982) to estimate the OH content in damaged zircon. This calibration 


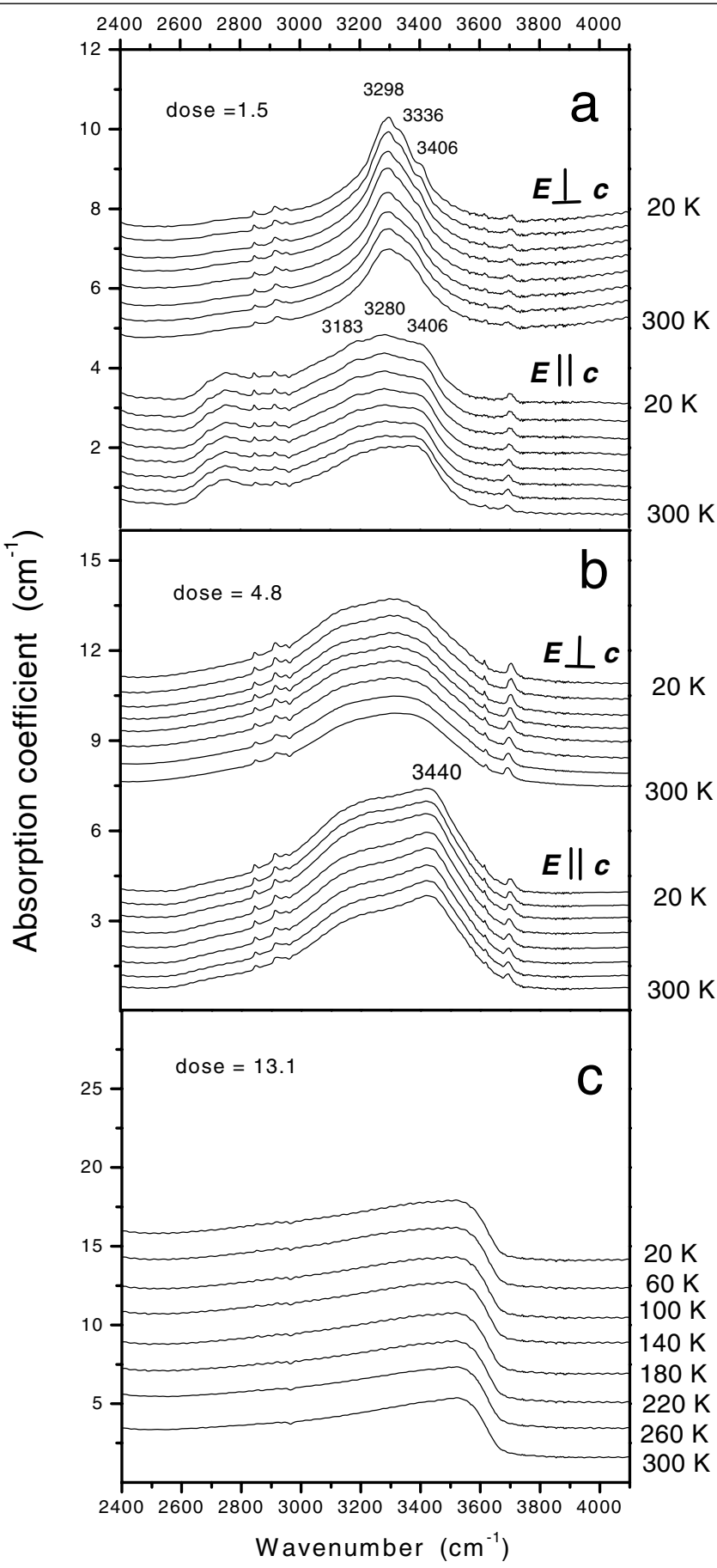

Figure 5. OH spectra of zircon with different degrees of damage between 20 and $300 \mathrm{~K}$ (the temperature interval $=40 \mathrm{~K}) .(a)$ dose $=1.5,(b) 4.8$, and $(c) 13.1 \times 10^{18} \alpha$-events $\mathrm{g}^{-1}$. The sample with a dose of $1.5 \times 10^{18} \alpha$-events $\mathrm{g}^{-1}$ shows relatively strong temperature responses, revealing $\mathrm{OH}$ bands at 3298,3336 , and $3406 \mathrm{~cm}^{-1}$ for $\boldsymbol{E} \perp \boldsymbol{c}$, and 3183,3280 , and $3406 \mathrm{~cm}^{-1}$ for $\boldsymbol{E} \| \boldsymbol{c}$ at $20 \mathrm{~K}$. The spectra for the sample with a dose of $13.1 \times 10^{18} \alpha$-events $\mathrm{g}^{-1}$ were obtained from sample plates with unknown crystallographic orientations because of their isotropy. The sharp weak signals near 2846,2952 , and $2917 \mathrm{~cm}^{-1}$ are caused absorption from the IR instruments. 


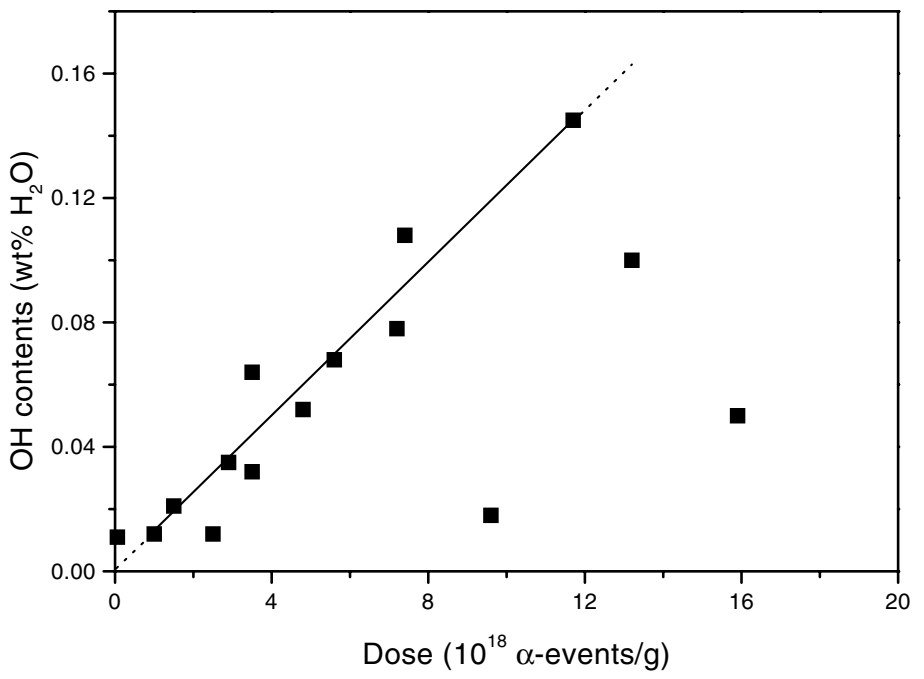

Figure 6. $\mathrm{OH}$ content of zircon as a function of radiation dose. The estimate of the $\mathrm{OH}$ concentration is obtained using the calibration of Paterson (1982) (please see the related text for details). The generally higher $\mathrm{OH}$ content for damaged samples shows that metamictization is one of the causes for the higher $\mathrm{OH}$ content in heavily damaged samples. The scattering data in the high-dose region indicate that $\mathrm{OH}$ is not the only parameter that affects the $\mathrm{OH}$ contents.

has been used to determine $\mathrm{OH}$ contents in metamict minerals (Woodhead et al 1991b, Zhang et al 2001). According to Paterson (1982), the $\mathrm{OH}$ content can be worked out using the equation:

$$
c=\int \frac{K(v)}{150 \gamma(3780-v)} \mathrm{d} v
$$

where $c$ is the molar concentration, $K$ the absorption coefficient, $\gamma$ the orientation factor, and $v$ the wavenumber; $\gamma=1 / 3$ was used for heavily damaged samples (dose $>10 \times 10^{18}$ $\alpha$-events $\mathrm{g}^{-1}$ ) because their spectral features are isotropic and $c$ is in units of $(\mathrm{mol} \mathrm{H}) \mathrm{L}^{-1}$. For crystalline and intermediately damaged zircons, $\gamma=1 / 2$ and 1 were used for the spectra with $\boldsymbol{E} \perp \boldsymbol{c}$ and $\boldsymbol{E} \| \boldsymbol{c}$, respectively. The total content results from the sum of the two components. Since Paterson (1982) used also glasses for the calibration, the calibration diagram is considered acceptable for the estimation of water in metamict substances. In a recent paper of Libowitzky and Rossman (1997), this diagram was essentially confirmed by calibration with crystalline minerals. The estimated $\mathrm{OH}$ contents from our measured data are shown in figure 6.

\subsection{U-ion spectra}

The absorption lines of crystalline zircon between 4000 and $11000 \mathrm{~cm}^{-1}$ are mainly due to $\mathrm{U}$ ions (figure $7(a)$ ). The first overtones of the $\mathrm{OH}$ species and the combinations of $\mathrm{OH}$ stretching with the framework are expected to appear near 7200 and $4500 \mathrm{~cm}^{-1}$, respectively, but they are too weak to be detected due to relatively low $\mathrm{OH}$ contents and small sample thickness. In crystalline zircon, the $\mathrm{Z}_{\mathrm{r}}^{+4}$ site (with symmetry $\mathrm{D}_{2 \mathrm{~d}}$ ) can be occupied by the uranium ions. The electronic energy levels of $\mathrm{U}^{4+}$ and identification of the $\mathrm{U}^{4+}$ spectrum were obtained for U-doped synthetic zircon (Richman et al 1967, Vance and Mackey 1978). The U energy levels can be labelled in terms of five irreducible representations of the $\mathrm{D}_{2 \mathrm{~d}}$ point group: four singlets $\Gamma_{1}, \Gamma_{2}, \Gamma_{3}, \Gamma_{4}$ and one doublet $\Gamma_{5}$. The degenerate $5 \mathrm{f}^{2}(\mathrm{SL}) \mathrm{J}$ terms split into 70 levels: 
$16 \Gamma_{1}+9 \Gamma_{2}+12 \Gamma_{3}+12 \Gamma_{4}+21 \Gamma_{5}$, i.e., 49 singlets $\Gamma_{1}, \Gamma_{2}, \Gamma_{3}, \Gamma_{4}$ and 21 doublets $\Gamma_{5}$. For crystalline zircon, our data are consistent with published results (Richman et al 1967, Vance and Mackey 1978). Absorption lines near 6668 and $9030 \mathrm{~cm}^{-1}$ were observed in this study, and they were assigned as signals due to $\mathrm{U}^{5+}$ in optical and Zeeman studies (Vance and Mackey $1974,1975)$. The presence of $\mathrm{U}^{5+}$ in damaged zircon is surprising, although $\mathrm{U}^{5+}$ has been observed in other minerals (Burns and Finch 1999). Judd and Runciman (1976) proposed that it was due to $\Gamma_{6} \rightarrow \Gamma_{6}$ and $\Gamma_{7} \rightarrow \Gamma_{7}$ transitions. Experimental results (Vance and Mackey 1978) confirmed the prediction and revealed that there was no accidental degeneracy in the ground state of $U$ ions. They found that it was caused by impurity-induced new transitions rather than radiation-damage-induced signals. The observation of strong signals from these two lines in crystalline and weakly damaged zircon support the results of Vance and Mackey (1978). No evidence for the presence of $\mathrm{U}^{6+}$ was observed in the U-ion spectrum of zircon by Vance and Mackey (1974). The effects of radiation on the structure of zircon are characterized by three types of spectral variation.

(1) The systematic broadening of the uranium spectra (figures $7(a)$ and $(b)$ ) with increasing radiation dosage reflects radiation-induced damage and modifications of local structures. The linewidth for weakly damaged zircon (e.g., dose $=1.0 \times 10^{18} \alpha$-events $\mathrm{g}^{-1}$ ) is around $50 \mathrm{~cm}^{-1}$ for the $\mathrm{U}^{4+}$ signal near $4833 \mathrm{~cm}^{-1}$. It becomes more than $200 \mathrm{~cm}^{-1}$ in samples with dose values higher than $5 \times 10^{18} \alpha$-events $\mathrm{g}^{-1}$.

(2) Dramatic intensity changes were recorded. The intensity changes in the U-ion spectrum of zircon are related to two different causes: increase of $U$ concentration and radiation damage. These two factors have opposite effects on the intensity. In comparison with undamaged samples, the increase in intensity in weakly damaged samples is mainly due to their relatively high $U$ concentrations. A close linear correlation between the intensity of the $\mathrm{U}^{4+}$ spectrum and the $\mathrm{U}$ concentration is observed (figure 8 ) and the results are consistent with the data reported by Vance and Mackey (1974), suggesting that these lines are due to $U$ ions. The effect of radiation damage on the intensity can be seen more clearly in samples with an intermediate degree of damage, where the signals due to amorphous regions show broad features for both $\boldsymbol{E} \perp \boldsymbol{c}$ and $\boldsymbol{E} \| \boldsymbol{c}$, and signals related to crystalline regions still exhibit relatively sharp and anisotropic bands. With increasing degree of damage, the relative intensity of the amorphous phase increases further, whereas the signals of crystalline domains become undetectable.

(3) We noted in slightly and weakly damaged samples $\left(0.06-1.5 \times 10^{18} \alpha\right.$-events $\left.\mathrm{g}^{-1}\right) \mathrm{a}$ systematic change of peak profiles occurred: the $\mathrm{U}^{5+}$ signal near $6668 \mathrm{~cm}^{-1}$ became weaker with increasing degree of damage whereas a new peak appeared near $6650 \mathrm{~cm}^{-1}$ (figures $7(a)$ and $(b)$; the data shown in figure $7(b)$ are normalized to show the detailed changes). A similar change was also recorded for the $\mathrm{U}^{5+}$ line near $9030 \mathrm{~cm}^{-1}$ in the spectra with $\boldsymbol{E} \| \boldsymbol{c}$. The peak near $6650 \mathrm{~cm}^{-1}$ weakened in intensity with further increasing radiation dose and became unresolvable above $6 \times 10^{18} \alpha$-events $\mathrm{g}^{-1}$ (figure $7(a)$ ). Data from an annealed zircon (see below) show that the $6668 \mathrm{~cm}^{-1}$ band was recovered after high-temperature annealing. This indicates that radiation damage, instead of chemical impurities, accounts for the disappearance of the $6668 \mathrm{~cm}^{-1}$ line, the appearance of the $6650 \mathrm{~cm}^{-1}$ signal (figure 7(b)), and the dramatic decrease in intensity for the $6650 \mathrm{~cm}^{-1}$ signal in the higher-dose range.

For heavily damaged zircon, the U-ion spectra are dominated by two broad spectral features with relatively strong intensity in the regions of $4500-5500 \mathrm{~cm}^{-1}$ and $8400-10600 \mathrm{~cm}^{-1}$ (figure $7(a)$ ). The former is centred near $4800 \mathrm{~cm}^{-1}$, which is close to the $\mathrm{U}^{4+}$ band near $4833 \mathrm{~cm}^{-1}$. The latter spreads over a large frequency region, and it appears to show several local 

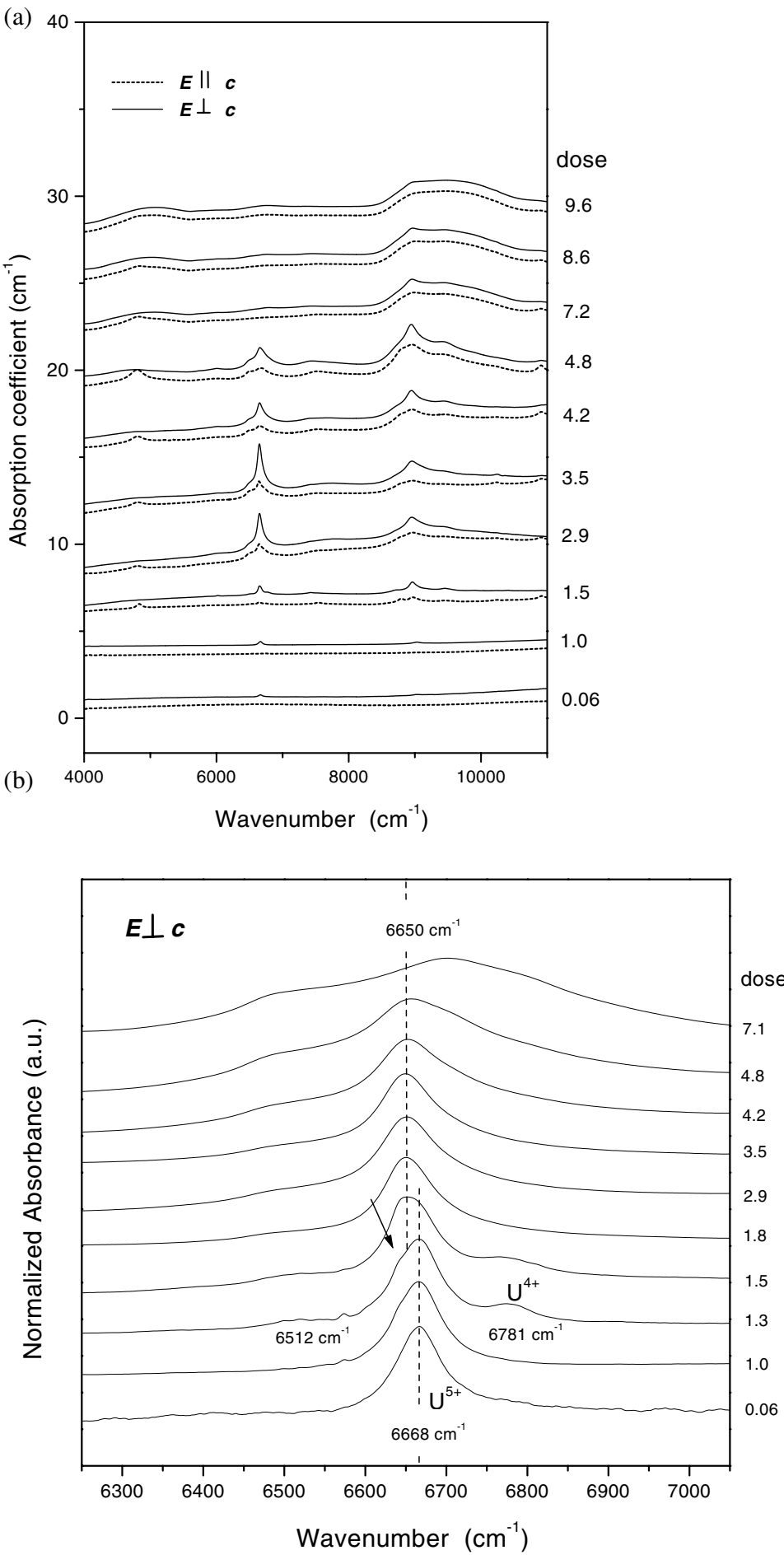

Figure 7. U-ion spectra. (a) Between 4000 and $11000 \mathrm{~cm}^{-1}$. The solid curves represent data with $\boldsymbol{E} \perp \boldsymbol{c}$ and the short-dashed curves those for $\boldsymbol{E} \| \boldsymbol{c}$. (b) Spectra $(\boldsymbol{E} \perp \boldsymbol{c})$ between 6200 and $7100 \mathrm{~cm}^{-1}$, normalized to show detailed changes for the band near $6668 \mathrm{~cm}^{-1}$ and the appearance of new bands. 


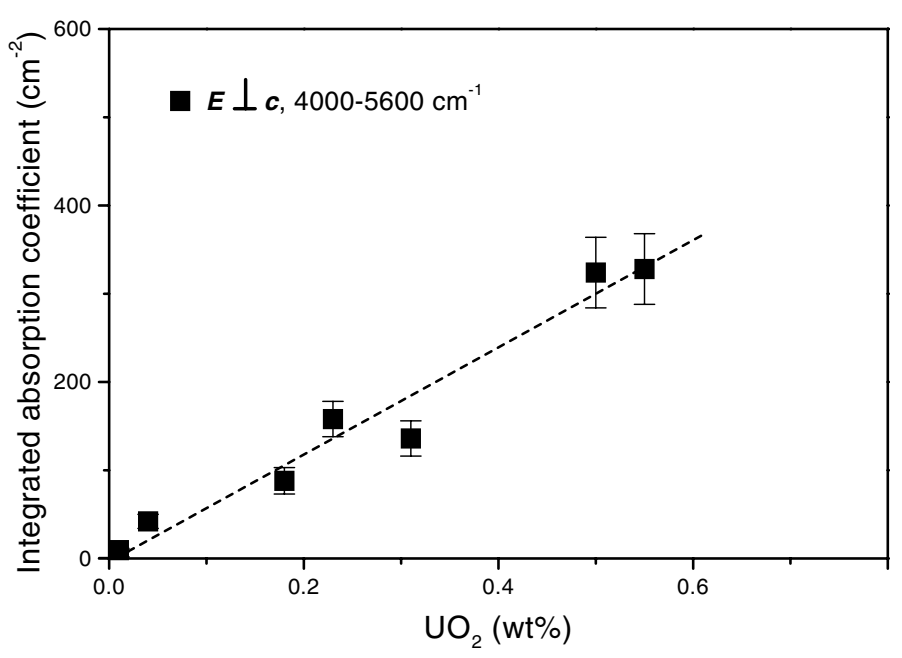

Figure 8. The integrated absorption coefficient between 4000 and $5600 \mathrm{~cm}^{-1}(\boldsymbol{E} \perp \boldsymbol{c})$ as a function of uranium concentration. The line is a visual guide.

maxima. A weak local maximum near $6750 \mathrm{~cm}^{-1}$ also appears for highly damaged samples. Although it is broad and has relatively low intensity, it is resolvable (e.g., for the sample with dose $=9.6 \times 10^{18} \alpha$-events $\mathrm{g}^{-1}$ in figure $7(a)$ ). The general shape of the U-ion spectrum of the crystalline zircon is somehow still preserved for highly damaged zircon (figure 7(a)) although the $\mathrm{U}^{5+}$ signals decrease dramatically with metamictization. This observation implies that some kinds of short-range order or local order abound $\mathrm{U}$ ions (i.e., abound $\mathrm{Zr}$ sites) may still persist in the metamict state of zircon. There are significant differences between the U-ion spectra of the metamict zircon and the $\mathrm{UO}_{2}\left(\mathrm{UO}_{2}\right.$ spectrum that was reported by Griffiths and Hubbard (1991)), so the possibility of the formation of $\mathrm{UO}_{2}$ can be ruled out.

\subsection{Spectral differences between metamict and decomposed zircons}

The presence of tetragonal $\mathrm{ZrO}_{2}$ and $\mathrm{SiO}_{2}$ glass was observed in only one natural zircon among a large number of zircon samples with a large range of radiation dose (Zhang et al 2000c). The sample is a green gemstone, like most heavily damaged samples analysed. However, it shows Raman signals of $\mathrm{ZrSiO}_{4}$ and additional sharp Raman bands at 146, 260, 312, 460, and $642 \mathrm{~cm}^{-1}$ characteristic of tetragonal $\mathrm{ZrO}_{2}$ (Zhang et al 2000c). X-ray diffraction data show that the sample is partially metamict. This decomposed zircon shows Si-O overtone and combination bands very different from those for the metamict zircon (figure 9). With $\boldsymbol{E} \perp \boldsymbol{c}$, it exhibits an intense $\mathrm{Si}-\mathrm{O}$ stretching overtone at $1869 \mathrm{~cm}^{-1}$ accompanied with a shoulder near $1993 \mathrm{~cm}^{-1}$. These features look more similar to those of $\mathrm{SiO}_{2}$ glass (with bands at 1631,1868 , 1984 , and $2261 \mathrm{~cm}^{-1}$ ) than those of radiation-damaged zircon. In particular, the decomposed zircon shows an isotropic band near $2261 \mathrm{~cm}^{-1}$ which also appears in $\mathrm{SiO}_{2}$ glass, but not in other zircon samples. This band is due to the overtone of the $\mathrm{Si}-\mathrm{O}$ stretching near $1115 \mathrm{~cm}^{-1}$ in $\mathrm{SiO}_{2}$ glass. This observation confirms that this sample contains $\mathrm{SiO}_{2}$ glass. The anisotropic spectral features (the bands at 1513 and $1597 \mathrm{~cm}^{-1}$ for $\boldsymbol{E} \perp \boldsymbol{c}, 1537,1799$, and $1933 \mathrm{~cm}^{-1}$ for $\boldsymbol{E} \| \boldsymbol{c}$ ) and the strong intensity for this decomposed sample indicate a significant amount of $\mathrm{ZrSiO}_{4}$ phase, consistent with Raman and x-ray observations. The two bands near 3418 and $3632 \mathrm{~cm}^{-1}$ for $\boldsymbol{E} \| \boldsymbol{c}$ (figure 9) are considered to be due to $\mathrm{OH}$ species from the remaining 


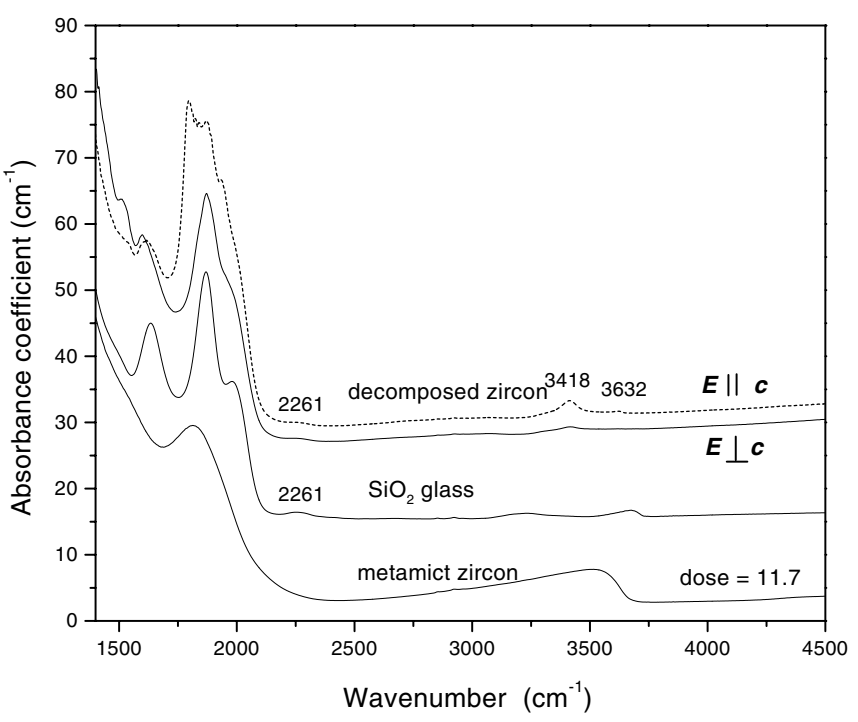

Figure 9. Spectral similarities between $\mathrm{SiO}_{2}$ glass and decomposed zircon containing $\mathrm{SiO}_{2}, \mathrm{ZrO}_{2}$, and $\mathrm{ZrSiO}_{4}$. Metamict zircon shows spectral features different from those for decomposed zircon. The spectrum of $\mathrm{SiO}_{2}$ glass is normalized to that of the decomposed zircon to show the details. The bands near 1631, 1686, 1948, and $2261 \mathrm{~cm}^{-1}$ in $\mathrm{SiO}_{2}$ glass are due to overtones and combinations of $\mathrm{Si}-\mathrm{O}$ bands.

crystalline zircon in the sample because of their anisotropy. Tetragonal $\mathrm{ZrO}_{2}$ and glassy $\mathrm{SiO}_{2}$ phases in decomposed zircons are randomly orientated (Capitani et al 2000). Due to a lack of information about the thermal history of the sample, it is difficult to rule out the possibility that the presence of $\mathrm{ZrO}_{2}$ and $\mathrm{SiO}_{2}$ is due to its previously undergoing a high-temperature condition. In fact, this decomposed sample shows spectra with very similar features to those of a thermally treated metamict zircon in which $\mathrm{SiO}_{2}$ and $\mathrm{ZrO}_{2}$ were seen (see a later section). The $\mathrm{OH}$ spectrum of this decomposed sample exhibits only two relatively sharp bands near 3422 and $3615 \mathrm{~cm}^{-1}$, in contrast to $\mathrm{OH}$ spectra of other zircon samples. This difference could be mainly due to the structural differences between this decomposed zircon and the metamict zircon. Our results also show clearly that the characteristic Si-O multi-phonon spectrum of highly damaged zircon is very different from that of $\mathrm{SiO}_{2}$ glass, suggesting that $\mathrm{Si}$ does not exist as $\mathrm{SiO}_{2}$ glass in the metamict state of zircon, and supporting previous IR and Raman observations of Zhang et al (2000b, 2000c). In contrast to the well-resolved Si-O signals in $\mathrm{SiO}_{2}$ glass (figure 9), metamict zircon shows a broad feature with a local maximum near $1818 \mathrm{~cm}^{-1}$. This implies a much more complex local configuration of $\mathrm{SiO}_{4}$ tetrahedra in metamict zircon than that of $\mathrm{SiO}_{2}$ glass.

\subsection{Thermal annealing}

A zircon crystal from Sri Lanka (with a dose of $15.9 \times 10^{18} \alpha$-events $\mathrm{g}^{-1}$ ) was annealed in time steps of $1 \mathrm{~h}$ at different temperatures in a $\mathrm{N}_{2}$ atmosphere. The IR reflectance data on $\mathrm{Si}-\mathrm{O}$ bands (650-1400 $\mathrm{cm}^{-1}$, room temperature-1800 K) of this annealed crystal were published previously (Zhang et al 2000b). For the reasons explained in the experimental section, it was impossible to orient this high-dose sample crystallographically, and only unpolarized spectra were recorded. The two-phonon spectra $\left(1400-2500 \mathrm{~cm}^{-1}\right)$ of the annealed sample are shown in figure $10(a)$. No significant spectral variations were seen at temperatures below $1000 \mathrm{~K}$. 
A broad shoulder near $1948 \mathrm{~cm}^{-1}$ appears near $1100 \mathrm{~K}$. This feature becomes more visible in the $1200 \mathrm{~K}$ spectrum, and the spectral shape (figure 10(a)) looks similar to that of the decomposed sample in figure 9. This observation indicates that the appearance of $\mathrm{SiO}_{2}$ glass resulted from the partial decomposition of metamict $\mathrm{ZrSiO}_{4}$. The Raman spectrum of this sample annealed at 1100 and $1200 \mathrm{~K}$ also shows the presence of tetragonal $\mathrm{ZrO}_{2}$. The spectra at 1400 and $1500 \mathrm{~K}$ show the broad characteristic signals of crystalline $\mathrm{ZrSiO}_{4}$ near $1515,1592,1595,1836,1871$, 1903, 1950, 1992, 2018 and $2061 \mathrm{~cm}^{-1}$ (obtained using the secondary-derivative method), suggesting significant crystal growth of $\mathrm{ZrSiO}_{4}$. Further increasing the temperature leads to a sharpening of these lines and an increase in their intensity. The unpolarized spectra of this sample between 1600 and $1800 \mathrm{~K}$, in fact, look more like the polarized spectra of crystalline samples with $\boldsymbol{E} \perp \boldsymbol{c}$ shown in figure 2(a). In the case of unpolarized incident radiation, the spectral feature of the sample annealed at $1800 \mathrm{~K}$ can only be obtained when the sample is like a 'single crystal' and its $\boldsymbol{c}$-axis is approximately parallel to the incident beam. This implies that the sample is somewhat anisotropic instead of polycrystalline. A polycrystalline sample should show IR spectra with principal components with $\boldsymbol{E} \| \boldsymbol{c}$ and $\boldsymbol{E} \perp \boldsymbol{c}$. X-ray measurements of the sample crystal annealed at $1800 \mathrm{~K}$ showed diffraction spots rather than powder rings, suggesting that it is not a polycrystal, but a crystal containing mainly a number of big 'domains' or sub-crystals with closely aligned crystallographic orientations.

The recrystallization in damaged zircon is also revealed by systematic changes in $\mathrm{U}^{4+}$ and $\mathrm{U}^{5+}$ spectra (figure $10(b)$ ). The relative integrated absorbance (the integrated absorbance value of the untreated sample was set as zero) between $6200-7000 \mathrm{~cm}^{-1}$ was calculated to show the effect of annealing temperature (figure 10(c)). This frequency range was chosen, because radiation damage causes the bands near $6650 \mathrm{~cm}^{-1}$ to become very broad and almost undetectable in high-dose cases (figures $7(a)$ and $(b)$ ). The integration shows a weak increase starting near $1100 \mathrm{~K}$. This is due to the appearance of weak signals of crystalline $\mathrm{ZrSiO}_{4}$ as observed by Raman spectroscopy. Above $1100 \mathrm{~K}, \mathrm{UO}_{2}$ could also exist, because $\mathrm{SiO}_{2}$ and $\mathrm{ZrO}_{2}$ were observed in this annealed sample by Raman spectroscopy. However, the volume of the possible $\mathrm{UO}_{2}$ phase must be very small because we did not detect the characteristic signals of $\mathrm{UO}_{2}$ reported by Griffiths and Hubbard (1991). The dramatic increase of U ions signals occurred near $1400 \mathrm{~K}$ (figure $10(c)$ ) and this indicates that the growth of $\mathrm{ZrSiO}_{4}$ resulted from reaction of $\mathrm{ZrO}_{2}$ and $\mathrm{SiO}_{2}$ as reported previously in Raman IR studies (Zhang et al 2000a, 2000b).

\section{Discussion}

Our IR results show clearly that the contents of hydrous species in zircon are affected by metamictization. This is consistent with the observation of Woodhead et al (1991b). As shown in figure 6, the damaged samples tend to contain higher $\mathrm{OH}$ concentrations, but we also note that not all the data points fall on a line, especially for some highly damaged samples. The results imply that although the metamictization in zircon tends to result in higher $\mathrm{OH}$ contents, $\mathrm{OH}$ species are not necessarily required in the metamict state of zircon, i.e., they do not act to stabilize the metamict state. Our results also indicate that the degree of radiation damage may not be the only parameter affecting the $\mathrm{OH}$ content. It is likely that metamictization leads to additional sites for $\mathrm{OH}$ species, while the total $\mathrm{OH}$ contents may also be affected by other factors (e.g., geological environments and thermal history).

By comparing the $\mathrm{OH}$ species in metamict titanite $\left(\mathrm{CaTiSiO}_{5}\right)$ ( $\mathrm{Zhang}$ et al $\left.2000 \mathrm{~d}\right)$, we note that $\mathrm{OH}$ species in metamict titanite and zircon show different responses to radiation damage. In titanite, crystalline regions show anisotropic $\mathrm{OH}$ absorption signals near $3486 \mathrm{~cm}^{-1}$ that are due to $\mathrm{OH}$ stretching at the $\mathrm{O}(1)$ site and exhibit an absorption maximum when $\boldsymbol{E}$ is approximately 

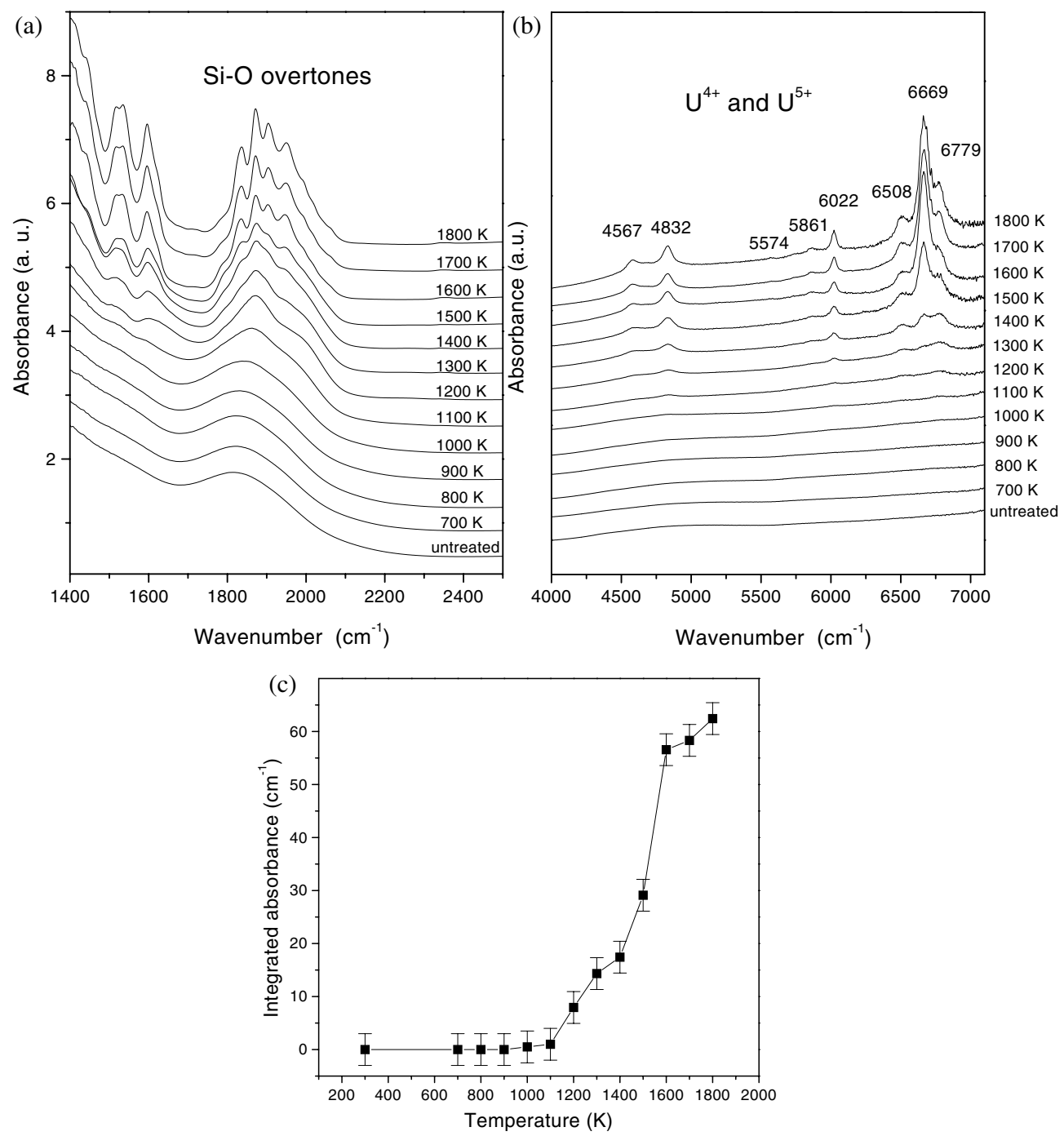

Figure 10. The effects of thermal annealing between room temperature and $1800 \mathrm{~K}$ on a zircon crystal with a dose of $15.9 \times 10^{18} \alpha$-events $\mathrm{g}^{-1}$ and a thickness of $500 \mu \mathrm{m}$. (a) The multi-phonon spectrum between 1400 and $2500 \mathrm{~cm}^{-1}$. The spectral changes near $1985 \mathrm{~cm}^{-1}$ taking place between 1100 and $1200 \mathrm{~K}$ are due to the occurrence of the thermally induced decomposition of $\mathrm{ZrSiO}_{4}$ into $\mathrm{SiO}_{2}$ and tetragonal $\mathrm{ZrO}_{2}$ as seen by Raman investigation (Zhang et al 2000a) and IR reflectance measurement (Zhang et al 2000b). (b) $\mathrm{U}^{4+}$ and $\mathrm{U}^{5+}$ spectra between 4000 and $7100 \mathrm{~cm}^{-1}$. The spectra were recorded using a Globar source, a $\mathrm{KBr}$ beam splitter, and an MCT detector. (c) The integrated absorbance for the features between 6200 and $7000 \mathrm{~cm}^{-1}$ as a function of annealing temperature.

parallel to $\boldsymbol{n}_{\alpha}$ (Isetti and Penco 1968, Beran 1970), whereas metamictization produces isotropic $\mathrm{OH}$ features (Salje et al 2000, Zhang et al 2001). With increasing degree of damage, the $\mathrm{OH}$ spectra are seen as a superposition of the isotropic and anisotropic signals. In contrast, new anisotropic $\mathrm{OH}$ species appear in zircon with intermediate degrees of damage. They coexist with signals from the amorphized phase. As a result, the broad spectral features between 2500 and $3500 \mathrm{~cm}^{-1}$ in these zircon samples are still weakly anisotropic. The significant spectral 
changes in the dose range of $1.0-1.5 \times 10^{18} \alpha$-events $\mathrm{g}^{-1}$ (figure 4) may result from the formation of new $\mathrm{OH}$ sites in crystalline domains and the appearance of the new $\mathrm{OH}$ species related to the formation of amorphized phase. The signals near 3183,3280 , and $3406 \mathrm{~cm}^{-1}$ for $\boldsymbol{E} \| \boldsymbol{c}$, and 3298, 3336, and $3406 \mathrm{~cm}^{-1}$ for $\boldsymbol{E} \perp \boldsymbol{c}$ for a weakly damaged sample (with a dose of $1.5 \times 10^{18} \alpha$-events $\mathrm{g}^{-1}$ shown in figure $\left.5(a)\right)$ must be related to the distorted crystalline materials, for they are relatively sharp and show clearly spectral anisotropy. The contribution from the $\mathrm{OH}$ species related to the amorphized parts is expected to show broad and isotropic spectral features, and they are unlikely to be the principal components in this sample as its main spectral features are very different from those of heavily damaged samples. At this stage, it is impossible to access any potential influence of chemical impurities on the $\mathrm{OH}$ species of zircon, unfortunately. Their roles can be complex and they are beyond the scope of this study. In a recent study of $\mathrm{OH}$ species in titanite (Zhang et al 2001), the $\mathrm{OH}$ contents in the crystalline domains and the amorphized phase could be estimated because the $\mathrm{OH}$ spectra are essentially the superpositions of the two contributions. In contrast, for the case of zircon, it is impossible or difficult to estimate the portions of $\mathrm{OH}$ contents in the different regions. The problem, which prevents us from analysing the data further, is how to distinguish the contribution of $\mathrm{OH}$ species in the crystalline domains from those in the amorphized regions. We consider that the formation of the new anisotropic $\mathrm{OH}$ species in the samples with intermediate degrees of damage is the main cause for the different thermal behaviour of $\mathrm{OH}$ species observed at high temperatures in metamict zircon (Woodhead et al 1991b) and titanite (Zhang et al 2001).

One of the important questions related to the metamictization of zircon is why the moderately damaged samples generally show some characteristic signals (e.g. in X-ray diffraction, vibration modes, $\mathrm{OH}$ and $\mathrm{U}$ ions) which are absent for undamaged and highly damaged zircon samples. These signals appear related to a crystalline phase as they relatively sharp. In an X-ray and optical investigation (Holland and Gottfried 1955), it was observed that a systematic development and disappearance of an extra peak near $2 \theta$ of $35^{\circ}-36.5^{\circ}$ occurred with increasing degree of $\alpha$-decay radiation damage. The authors found no appreciable variability that could be related to inhomogeneity, and proposed the formation of an intermediate polycrystalline phase with an intermediate dose. In an IR spectroscopic study (Zhang and Salje 2001), an extra absorption peak near $796 \mathrm{~cm}^{-1}$ was observed in moderately damaged zircon samples. This IR signal did not appear in well-crystallized samples (e.g. samples with doses $<1.5 \times 10^{18} \alpha$-events $\mathrm{g}^{-1}$ ), but it was detected in all samples with intermediate degrees of damage. For samples with doses between 1.5 and 6.5 (in units of $10^{18} \alpha$-events $g^{-1}$ ), this peak appeared to have similar values of intensity. With further increasing dose, this peak becomes weaker, and is eventually undetectable for the heavily damaged samples (e.g., samples with doses of 9.6 and $23.5 \times 10^{18} \alpha$-events $\left.\mathrm{g}^{-1}\right)$. This peak has appeared in some IR spectra reported previously (e.g., Vance (1975), Woodhead et al (1991a)) although it did not seem to have drawn the attention of some authors. It was also observed in reflection spectra of moderately damaged zircon annealed at high temperatures (Zhang et al 2000b). According to theoretical and experimental work (Dawson et al 1971), $\mathrm{ZrSiO}_{4}$ structure does not have an IR band near $796 \mathrm{~cm}^{-1}$. In OH spectra, the spectra of zircon with intermediate degrees of damage show characteristic patterns, which are very different from those of lower- or high-dose regions. What is more, the line near $6667 \mathrm{~cm}^{-1}$ in the U-ion spectrum shows anomalous changes near doses of $1.5 \times 10^{18} \alpha$-events $\mathrm{g}^{-1}$ (i.e., the appearance of an extra signal near $6650 \mathrm{~cm}^{-1}$ ) (figure $7(b)$ ). Eventually, the $6650 \mathrm{~cm}^{-1}$ line becomes undetectable in the spectrum of a sample with a dose of $7.1 \times 10^{18} \alpha$-events $\mathrm{g}^{-1}$ (figure $7(b)$ ). We believe that these anomalies detected by different analytic methods do not appear accidentally in the moderately damaged samples. They reflect the radiation-induced damage in crystalline regions which are 'seen' by vibrational phonons, $\mathrm{OH}$ species, and $\mathrm{U}$ ions. 
$\mathrm{OH}$ and $\mathrm{U}$ ions are defects in the structure of $\mathrm{ZrSiO}_{4}$. Their peak profiles (number of bands, peak positions, and shapes) are very sensitive to their local surroundings. They can be affected by the structural modification surrounding oxygen atoms. The modification may be also correlated with observed changes in cell parameters (Holland and Gottfried 1955, Murakami et al 1991) and vibrational bands (Zhang et al 2000c, Zhang and Salje 2001) in this dose range. These changes appear to suggest the existence of an intermediate state with a modified local symmetry in the moderately damaged zircon samples. We consider that chemical impurities may not be the principal cause of the spectral changes for the following reasons. Firstly, the Sri Lanka zircon samples have relatively low concentrations of chemical impurities (for information on the chemical compositions of the samples, see Zhang et al (2000a, 2000c)) in comparison with zircon from other localities, although one cannot rule out the possible effects of chemical impurities on $\mathrm{OH}$ spectra. In addition, the $\mathrm{OH}$ spectral features show systematic variations outside the range of $1.0-10 \times 10^{18} \alpha$-events $g^{-1}$ (figures $4(a)$ and $(b)$ ) which cannot be explained by chemical impurities. Furthermore, the spectral changes can be recovered through high-temperature annealing, suggesting that they are due to radiation damage.

Another possible cause for the change in $\mathrm{U}$ and $\mathrm{OH}$ spectra is radiation-induced ionization. During radioactive decays (i.e., $\alpha$-, $\beta$-, and $\gamma$-decays), ionization may take place and cause variations of the charge state of lattice defects. These changes may play a significant role in the microstructural evolution of irradiated materials and result in changes in other physical properties. As a result, the mobility of the defects may be affected (Bourgoin and Corbett 1978), and eventually the chemical durability and dissolubility may be altered. The radiationinduced reduction of $\mathrm{Fe}^{3+}$ to $\mathrm{Fe}^{2+}$ was reported in metamict titanite by Hawthorne et al (1991). Our results suggest that $\mathrm{U}^{4+}$ is still the principal oxidization state of $U$ in highly metamict zircon, although the data cannot completely rule out the possible presence of $\mathrm{U}^{6+}$ caused by metamictization of zircon. The presence of $\mathrm{U}^{4+}$ due to the daughter product of ${ }^{238} \mathrm{Pu}$ decay was recorded in $\mathrm{Pu}$-doped zircon using $\mathrm{x}$-ray absorption fine-structure spectroscopy at the $\mathrm{U}$ $\mathrm{L}_{\text {III }}$ edge (Hess et al 1998). The dramatic variations of intensity with increasing radiation dose shown by the $\mathrm{U}^{5+}$ bands near 6668 and $9030 \mathrm{~cm}^{-1}$ (figure $7(a)$ ) are puzzling. Further investigations are desirable to check the physical origins.

The systematic development of the signal near $3560 \mathrm{~cm}^{-1}$ (figures $4(a)$ and $(b)$ ) in the dose range of $4-10 \times 10^{18} \alpha$-events $\mathrm{g}^{-1}$ is surprising. This feature should be related to the amorphized phase, for it is isotropic (appearing when $\boldsymbol{E} \| \boldsymbol{c}$ and $\boldsymbol{E} \perp \boldsymbol{c}$ and for other orientations) and its intensity increases with increasing dose. Only very limited crystalline domains may remain in the high-dose case. Why zircon samples with such high doses show this $\mathrm{OH}$ feature is unclear. It is certainly related to new $\mathrm{OH}$ sites in these samples. It may suggest that the local configuration of the amorphized phase in the low-dose case could be modified with further damage. The development of this feature at high doses and the significant spectral change near $1.5 \times 10^{18} \alpha$-events $\mathrm{g}^{-1}$ (figures $4(a)$ and $(b)$ ) could also be related to the two percolation points discussed by Salje et al (1999).

Our study revealed that the absorption coefficient related to the maximum near $1875 \mathrm{~cm}^{-1}$ (the maximum shifts to near $1815 \mathrm{~cm}^{-1}$ in highly damaged samples) shows a dramatic decrease up to dose of $3.5 \times 10^{18} \alpha$-events $\mathrm{g}^{-1}$ and a systematic increase at higher dose values with increasing damage. As explained in earlier texts, the signals in this region are mainly associated with the two-phonon interactions of Si-O stretching. The observed change in fact reflects the decrease of crystalline phase fraction and the increase of amorphized phase fraction with increasing dose. Although the signal reaches its minimum near $3.5 \times 10^{18} \alpha$-events $\mathrm{g}^{-1}$, this does not mean that above this dose value zircon becomes fully metamict, because further spectral changes still take place at much higher doses (figures 1, 2(a) and $(b)$ ). In fact, X-ray diffraction, IR, and Raman measurements (Salje et al 1999, Zhang et al 2000b, 2000c, Zhang 
and Salje 2001), for the same samples, showed that crystalline domains of $\mathrm{ZrSiO}_{4}$ remained detectable even in samples with much higher dose values. In fact, as shown by Salje et al (1999), the fully metamict state can hardly be reached. We also note that the bands near $2700 \mathrm{~cm}^{-1}$, which are mainly due to second-overtone of $\mathrm{Si}-\mathrm{O}$ stretching, become undetectable when the dose is higher than $3.5 \times 10^{18} \alpha$-events $\mathrm{g}^{-1}$ as reported by Woodhead et al (1991a). This could be due to their relatively low intensity and overlap with $\mathrm{OH}$ species. By comparison with the first overtones of Si-O stretching near $1700-1800 \mathrm{~cm}^{-1}$, the bands near $2700 \mathrm{~cm}^{-1}$ are not ideal bands for the determination of the degree of damage in highly metamict zircon.

\section{Conclusions}

Near-IR spectroscopy has been used to investigate the metamictization process and the metamict state in zircon. The results from this study show that the effects of radiation on the crystal structure of zircon are characterized by a dramatic variation of intensity, a decrease in frequencies in multi-phonon bands, a change of spectral profile of $\mathrm{OH}$ species, a formation of new $\mathrm{OH}$ species, and new signals related to $\mathrm{U}$ ions. The data from moderately damaged zircon show the presence of new anisotropic $\mathrm{OH}$ species, implying radiation-induced new $\mathrm{OH}$ sites and structural modifications in the crystalline region of partially damaged zircon. The damaged zircons tend to contain higher $\mathrm{OH}$ concentrations. The results suggest that although the metamictization in zircon tends to result in higher $\mathrm{OH}$ contents, $\mathrm{OH}$ species are not necessarily required in the metamict state of zircon, i.e., they do not act to stabilize the metamict state. Our results also indicate that the degree of radiation damage may not be the only parameter affecting the $\mathrm{OH}$ content. Radiation damage causes dramatic changes in the $\mathrm{U}^{4+}$ and $\mathrm{U}^{5+}$ spectra of zircon. Our results show, for the first time, that radiation leads to the disappearance of the $\mathrm{U}^{5+}$ bands near 6668 and $9030 \mathrm{~cm}^{-1}$ and the occurrence of extra lines near 6650 and $8969 \mathrm{~cm}^{-1}$ at doses of around $1.5 \times 10^{18} \alpha$-events $\mathrm{g}^{-1}$. The general shape of the U-ion spectrum of the crystalline zircon is somehow still preserved for highly damaged zircon. There are significant differences between the U-ion spectra of the metamict zircon and those of $\mathrm{UO}_{2}$. Different spectral patterns were observed for metamict zircon and a decomposed zircon. The spectrum of the decomposed sample exhibits characterized signals of $\mathrm{SiO}_{2}$ glass in the $\mathrm{Si}-\mathrm{O}$ overtone region. Thermal annealing of highly metamict zircon at high temperatures results in decomposition into $\mathrm{SiO}_{2}$ and $\mathrm{ZrO}_{2}$ near $1100 \mathrm{~K}$. The recovery of Si-O stretching overtones and $\mathrm{U}^{4+}$ and $\mathrm{U}^{5+}$ bands near $1400 \mathrm{~K}$ indicates significant crystal growth of $\mathrm{ZrSiO}_{4}$.

\section{Acknowledgments}

The authors are indebted to the Sedgwick Museum of the University of Cambridge, UK; the Natural History Museum, London, UK; and the Mineralogisches Museum of Universität Hamburg, Germany for providing some of the samples used in this study. Thanks are due to William Lee for reading the original manuscript.

\section{References}

Aines R D and Rossman G R 1986 Am. Mineral. 711186

Beran A 1970 Tschermaks Mineral. Petrograph. Mitteil. 141

Bourgoin J C and Corbett J W 1978 Radiat. Eff. 36157

Burns P C and Finch R J 1999 Am. Mineral. 841456

Capitani G C, Leroux H, Doukhan J C, Ríos S, Zhang M and Salje E K H 2000 Phys. Chem. Minerals 27545

Caruba R, Baumer A, Ganteaume M and Iacconi P 1985 Am. Mineral. 701224 
Colombo M, Crosch J and Salje E K H 1999 J. Am. Ceram. Soc. 822711

Dawson P, Hargreave M M and Wilkinson G F 1971 J. Phys. C: Solid State Phys. 4240

Ellsworth S, Navrotsky A and Ewing R C 1994 Phys. Chem. Minerals 21140

Ewing R C 1994 Nucl. Instrum. Methods B 9122

Farges F 1994 Phys. Chem. Miner. 20504

Farnan I and Salje E K H 2001 J. Appl. Phys. 892084

Geisler T, Pidgeon R T, van Bronswijk W and Pleysier R 2001 Eur. J. Mineral. 131163

Griffiths T R and Hubbard H V S 1991 J. Nucl. Mater. 185243

Hawthorne F C et al 1991 Am. Mineral. 76370

Hazen R M and Finger L W 1979 Am. Mineral. 64157

Hess H J, Weber W J and Conradson S D 1998 J. Nucl. Mater. 254175

Holland H D and Gottfried D 1955 Acta Crystallogr. 8291

Isetti G and Penco A M 1968 Mineral. Petrograph. Acta 14115

Judd B R and Runciman W A 1976 Proc. R. Soc. A 35291

Libowitzky E and Rossman G R 1997 Am. Mineral. 821111

Meldrum A, Zinkle S J, Boatner L A and Ewing R C 1998 Nature 39556

Murakami T, Chakoumakos B C, Ewing R C, Lumpkin G R and Weber W J 1991 Am. Mineral. 761510

Paterson M S 1982 Bull. Minéral. 10520

Richman I, Kisliuk P and Wong E Y 1967 Phys. Rev. 155262

Ríos S and Salje E K H 1999 J. Phys.: Condens. Matter 118947

Ríos S, Salje E K H, Zhang M and Ewing R C 2000 J. Phys.: Condens. Matter 122401

Salje E K H, Chrosch J and Ewing R C 1999 Am. Mineral. 841107

Salje E K H, Zhang M and Groat L A 2000 Phase Transitions 71173

Trachenko K O, Dove M T and Salje E K H 2001 J. Phys.: Condens. Matter 131947

Vance E R 1975 Radiat. Eff. 241

Vance E R and Mackey D J 1974 J. Phys. C: Solid State Phys. 71898

Vance E R and Mackey D J 1975 J. Phys. C: Solid State Phys. 83439

Vance E R and Mackey D J 1978 Phys. Rev. 18185

Wasilewski P J, Senftle F E, Vaz J E, Thorpe A N and Alexander C C 1973 Radiat. Eff. 17191

Weber W J 1991 Radiat. Eff. Defects Solids 115341

Weber W J, Ewing R C and Wang L M 1994 J. Mater. Res. 9688

Woodhead J A, Rossman G R and Silver L T 1991a Am. Mineral. 7674

Woodhead J A, Rossman G R and Thomas A P 1991b Am. Mineral. 761533

Zhang M, Lee G A, Salje E K H and Beran A 2001 Am. Mineral. 86904

Zhang M and Salje E K H 2001 J. Phys.: Condens. Matter 133057

Zhang M, Salje E K H, Capitani G C, Leroux H, Clark A M and Schlüter J 2000a J. Phys.: Condens. Matter 12313

Zhang M, Salje E K H, Ewing R C, Farnan I, Ríos S, Schlüter J and Leggo P 2000b J. Phys.: Condens. Matter 12 5189

Zhang M, Salje E K H, Farnan I, Graeme-Barber A, Daniel P, Ewing R C, Clark A M and Leroux H 2000c J. Phys.: Condens. Matter 121915

Zhang M, Salje E K H, Malcherek T, Bismayer U and Groat L A 2000d Can. Mineral. 38119

Zhang M, Wruck B, Graeme-Barber A, Salje E K H and Carpenter M A 1996 Am. Mineral. 8192 